\title{
Myelopoiesis, metabolism and therapy: a crucial crossroads in cancer progression
}

\author{
Antonio Sica ${ }^{1,2, *}$, Valentina Guarneri $i^{3,4}$ and Alessandra Gennari $i^{5}$ \\ ${ }^{1}$ Department of Pharmaceutical Sciences, Università del Piemonte Orientale "Amedeo Avogadro", via Bovio 6, Novara, Italy. \\ ${ }^{2}$ Humanitas Clinical and Research Center, Via Manzoni 56, 20089 Rozzano, Milan, Italy. \\ ${ }^{3}$ Department of Surgery, Oncology and Gastroenterology, University of Padova. \\ ${ }^{4}$ Istituto Oncologico Veneto IOV I.R.C.C.S, Padova, Italy. \\ ${ }^{5}$ Division of Oncology, Department of Translational Medicine, University of Eastern Piedmont, Novara, Italy. \\ * Corresponding Author: \\ Antonio Sica, Department of Pharmaceutical Sciences, Università del Piemonte Orientale "Amedeo Avogadro", Via Bovio 6, Novara, \\ Italy; Tel: +39 (0)321 375881; Fax: +39 (0)321 375821; E-mail: antonio.sica@uniupo.it; antonio.sica@humanitasresearch.it
}

\begin{abstract}
Cancers promote immunological stresses that induce alterations of the myelopoietic output, defined as emergency myelopoiesis, which lead to the generation of different myeloid populations endowed with tumor-promoting activities. New evidence indicates that acquisition of this tumor-promoting phenotype by myeloid cells is the result of a multistep process, encompassing initial events originating into the bone marrow and later steps operating in the tumor microenvironment. The careful characterization of these sequential mechanisms is likely to offer new potential therapeutic opportunities. Here, we describe relevant mechanisms of myeloid cells reprogramming that instate immune dysfunctions and limit effective responses to anticancer therapy and discuss the influence that metabolic events, as well as chemotherapy, elicit on such events.
\end{abstract}

doi: $10.15698 /$ cst2019.09.197

Received originally: 11.04.2019

in revised form: 17.06.2019,

Accepted 19.06.2019,

Published 01.07.2019.

Keywords: cancer, emergency myelopoiesis, tumor-associated macrophages, myeloidderived suppressor cells, immune-metabolism, chemotherapy.

\author{
Abbreviatons: \\ $\alpha K G-\alpha$-ketoglutarate, \\ AMPK - adenosine monophosphate kinase, \\ $B C$ - breast cancer, \\ $B M$ - bone marrow, \\ $D C$ - dendritic cell, \\ G-CSF - granulocyte colony-stimulating factor, \\ HSC - hematopoietic stem cell, \\ M-CSF - macrophage colony-stimulating \\ factor, \\ MDSC-myeloid-derived suppressor cell, \\ NAMPT - nicotinamide \\ phosphoribosyltransferase, \\ pCR - pathologic complete response, \\ TAM - tumor-associated macrophage, \\ Treg-regulatory $T$ cell.
}

\section{INTRODUCTION}

The bone marrow (BM) is a primary lymphoid organ that hosts hematopoietic progenitors and presides over hematopoiesis, which is defined as the production of all types of blood cells. Under steady-state conditions, hematopoiesis is a strictly regulated process that consists of a series of cell lineage commitments, encompassing sequential steps of differentiation, including transition of hematopoietic stem cells (HSCs) to lymphoid and myeloid precursors and subsequently to mature immune cells, necessary to maintain the physiological levels of circulating leukocytes [1]. In stress/pathological conditions (e.g. infection and cancer), signals derived from the HSCs niche modify the magnitude and composition of the hematopoietic output, a feature of immune regulation defined as "emergency" hematopoiesis, to guarantee proper supply of both lymphoid and myeloid cells to increased demand [2]. In particular, in cancer altered myelopoiesis generates lineage-restricted hematopoietic progenitors, supporting the expansion of mature and immature myeloid cells endowed with tumorpromoting activities [3]. Within this scenario, tumorassociated macrophages (TAMs) and myeloid-derived sup- 
pressor cells (MDSCs) [4] are the main myeloid populations rising during tumor development and represent the final commitment of the protumoral reprogramming of the myeloid lineage. Moreover, Tie-2-expressing monocytes and tumor-associated neutrophils (TANs) infiltrate tumors, promoting angiogenesis and immunosuppression $[5,6]$.

"Emergency" myelopoiesis emerges in response to danger signals and is aimed at elimination of microbial threats, tissue repair and recovery of homeostatic conditions. Danger signals are sensed by myeloid cells through pattern recognition receptors (PRRs), able to detect pathogen-associated molecular patterns (PAMPs), conserved among entire classes of pathogens [7], as well as endogenous damage-associated molecular patterns (DAMPs), which are produced upon cellular stress and damage [8]. These events promote the production of cytokines and growth factors, which act through specific transcriptional programs that drive differentiation of myeloid cells.

Among these, interleukin-17A (IL-17A) promotes both granulocyte colony-stimulating factor (G-CSF)- and stemcell-factor-mediated neutrophilia [9] and supports G-CSFdriven "emergency" myelopoiesis[10]. IL-1 and IL-6 represent additional players in emergency myelopoiesis. In particular, IL-1 has been found to increase the proliferation and differentiation rate of HSCs [11] through induction of PU.1 and the consequent upregulation of both the macrophage colony-stimulating factor (M-CSF;Csf1r) and the granulocyte macrophage colony-stimulating factor (GM$\mathrm{CSF}$; $\mathrm{Sf} 2 \mathrm{ra}$ ) receptors. Interestingly, while chemotherapyinduced inflammation is a mechanism that reinforces aberrant myelopoiesis through the generation and expansion of MDSCs, IL-6 was confirmed to activate emergency myelopoiesis after myeloablation consequent to either cytotoxic treatment [12] or irradiation [13, 14]. Thus, the interplay between chemotherapy and inflammatory mediators critically controls the pathological expansion of tumorpromoting myeloid cells. Myelopoiesis is also critically affected by metabolism. In particular, cancer cells display increased glucose uptake and fermentation of glucose to lactate, even in the presence of completely functioning mitochondria. A major side effect of this event is immunosuppression, characterized by limited immunogenicity of cancer cells and restriction of the therapeutic efficacy of anticancer immunotherapy[15]. Correcting the pathological expansion of tumor-promoting myeloid cells during tumor growth appears therefore to be a promising strategy to improve anticancer responses and to generate more effective therapies.

\section{ORIGIN OF MYELOID SUPPRESSOR CELLS}

In acute inflammation, notably during acute infections, myeloid progenitors expand and differentiate into activated pro-inflammatory monocytes, which eventually migrate into tissues where they mature to macrophages and dendritic cells (DCs) $[16,17]$. Expansion of suppressor myeloid cells is peculiar to chronic inflammatory states (e.g. cancer, chronic infection and autoimmune disease), impairing the differentiation of myeloid progenitors into mature immune cells and leading to the expansion and accumulation suppressor myeloid cells, including MDSCs and TAMs [4]. Their expansion is an hallmark of cancer-immunosuppression and a major obstacle to anticancer treatments, since these populations exert a primary role in the organization of the immunosuppressive microenvironments $[18,19]$. The detailed description of the mechanisms used by TAMs and MDCSs to promote tumor growth has been widely described in other works $[3,20]$ and goes beyond the scope of this review. Beyond being highly heterogeneous, TAMs and MDSCs are also highly plastic [21] and the surrounding microenvironment influences their functions to promote tumor development and to suppress immune responses through multiple mechanisms, including: depletion of metabolites critical for T cell functions, expression of immune checkpoint inhibitors, secretion of immunosuppressive molecules, production of reactive oxygen and nitrogen species, regulation of lymphocyte homing, expansion of regulatory $T$ (Treg) cells [18]. In particular, TAMs are considered crucial orchestrators of cancer-related inflammation because they promote angiogenesis, immunosuppression, tissue remodeling and metastasis [20, 22]. The protumoral phenotype of TAMs is dictated by microenvironmental signals, which exploit the functional plasticity of macrophages, defined as the capacity to acquire a variety of functional states in response to different environmental stimuli. Indeed, in vitro macrophages activated by lipopolysaccharide (LPS) in the presence or absence of interferon- $\gamma$ (IFNY) (classically or M1/[LPS \pm IFN $]$-activated) and those stimulated by IL-4 (alternatively or $\mathrm{M} 2 /[\mathrm{IL}-4 \pm \mathrm{IL}-13]-$ activated) represent the extreme ends of a continuum of polarization states. Polarized macrophages differ in terms of receptors expression, cytokines/chemokines production, and effector functions. Although it is an oversimplification, the TAM's phenotype mostly resembles that of M2-like polarized macrophages. The phenotype of TAMs is strongly influenced by microphysiological conditions present in the surrounding microenvironment (e.g. hypoxia, interstitial hyperpression, low glucose levels) and molecularly and functionally distinct TAM subsets can simultaneously exist [23].

Along with TAMs, MDSCs are characterized by the capacity to suppress $T$ cell functions and support tumor progression $[3,17]$. These cells comprise at least two subsets: monocytic MDSCs (identified as CD11b+Ly6G-Ly6Chi cells in mouse and $\mathrm{CD} 11 \mathrm{~b}^{+} \mathrm{CD} 14^{+} \mathrm{HLA}-\mathrm{DR} \mathrm{R}^{\text {low/- }} \mathrm{CD} 15^{-}$cells in human) and granulocytic MDSCs (PMN-MDSCs, identified as CD11 b ${ }^{+}$Ly6G Ly6C $^{\circ}$ cells in mouse and CD11 $b^{+}$CD $14^{-}$CD $15^{+}$ or $\mathrm{CD} 11 \mathrm{~b}^{+} \mathrm{CD} 14^{-} \mathrm{CD} 66^{+}$cells in human) [24]. Despite the extensive literature on MDSCs, a consensus regarding the cellular definition of MDSC subsets has not yet been reached, as no specific markers exist to identify them unequivocally [24]. Nevertheless, due to the development of more sophisticated biochemical and gene expression profiling techniques, these cells are emerging as a pathologically activated population of immature myeloid cells. Therefore, on the basis of a panel of molecular, biochemical, and functional markers, an algorithmic approach to define cells as MDSCs has been proposed [17]. 
Globally, accumulation of myeloid progenitors and their differentiation to TAMs and MDSCs is the result of a process driven by cancer-related inflammation [25], involving: altered myelopoiesis; mobilization of myeloid precursors from the BM to periphery; recruitment of MDSCs and TAMs precursors into both secondary lymphoid organs and/or tumor tissues; functional diversion of myeloid cells in response to microenvironmental signals. This multistep process drives the reprogramming of myeloid cells towards a tumor-promoting phenotype and remotely controls the composition of the tumor-microenvironment. In support of this scenario, we recently showed that myeloid-specific expression of the retinoic-acid related orphan receptor (RORC1/RORY) marks advanced cancer-inflammation [26] and expansion of circulating RORC1 $1^{+}$myeloid cells is associated with increased number of both immature suppressive cells (MDSCs) and TAMs [26]. We also reported that the M-CSF elevates the myeloid cell levels of nicotinamide phosphoribosyltransferase (NAMPT), the rate-limiting enzyme in the NAD salvage pathway, which acts as negative regulator of the CXCR4 retention axis of hematopoietic cells in the BM [27], hence promoting mobilization of myeloid cells to periphery. In agreement, NAMPT inhibition prevented MDSCs mobilization, reactivated specific antitumor immunity and enhanced the antitumor activity of immune checkpoint inhibitors [27].

Additional evidences indicate that accumulation of TAMs and MDSCs in tumor tissues, as well as in metastasis, is guided by specific chemotactic pathways (eg. CCL2, MCSF, CXCL2) $[3,28]$, suggesting possible therapeutic strategies to limit their recruitment and contribution to tumor growth. Lastly, microenvironmental signals and conditions, such as immunosuppressive cytokines (eg, IL-10, TGF $\beta$ ) and hypoxia [29-31], dictate the final protumoral commitment of myeloid cells. Hence, this multistep process of myeloid cell reprogramming (Figure 1) may offer different levels of potential therapeutic interventions.

Similarly, activation and differentiation of DCs, the most potent antigen-presenting cells (APCs) of the immune system, is influenced by tumor growth, as well as by inflammatory and metabolic disorders [32]. Tumors alter host hematopoiesis and induce large numbers of immature DCs with immune suppressive properties. In addition, cancer cells produce immune suppressive factors (VEGF, IL-10, PGE2) that disable DC differentiation, maturation, migration, and functions [33]. Interestingly, while the 27 hydroxycholesterol (27HC) acts on HSCs via ER $\alpha$ to increase their proliferation and mobilization [34], oxysterols, that rise through enzymatic and non-enzymatic oxidation of cholesterol [35], interact with liver $X$ receptors (LXRs) exerting an anti-inflammatory role on macrophages and DCs [36]. In agreement, oxysterols produced by tumor cells impair antigen presentation by inhibiting CCR7 expression on DCs [37]. Furthermore, DCs' immunogenicity is hampered by both TAMs and MDSCs, through the production of copious amount of indoleamine 2,3 dioxygenase 1 (IDO1) that converts tryptophan into kynurenines [38]. DCs differentiation is also affected by the gut microbiota, which may play a determinant role in the response to anticancer therapies. In particular, cancer chemotherapy and immunotherapy cause damage to intestinal epithelial barrier allowing bacteria translocation and/or changes in microbial composition, producing an adjuvant effect $[39,40]$. Of relevance, Bifidobacterium species are associated with an anti-tumor response promoted by an enhanced activation of DCs, increased frequency of CD8+ T cells and greater response to anti-PD-L1 treatment [41]. Recent studies have also highlighted the role of energy metabolic pathways in the differentiation and function of myeloid cells [42]. In this regard, the deranged metabolic flux of cancer cells, characterized by aerobic glycolysis (Warburg effect) [47], results in the preferential conversion of pyruvate to lactate, which in turn impairs cytolytic T cell functions, and maturation of DCs [43].

\section{TRANSCRIPTIONAL CONTROL OF MYELOPOIESIS}

The transcriptional basis guiding emergency myelopoiesis has only been partially clarified. Whereas C/EBP $\alpha$ appears to be a major regulator of "steady-state" granulopoiesis [44], C/EBP 3 [45] and Signal Transducer and Activator of Transcription 3 (STAT3) [46] promote expansion and maturation of neutrophils under emergency conditions. Furthermore, while in acute inflammation the C/EBP $\alpha$ interacts with the p50 NF-kB subunit to stimulate neutrophil production [47], C/EBP $\beta$ is a critical regulator of altered myelopoiesis in cancer bearers, contributing to the accumulation of MDSC and to the creation of an immunosuppressive environment [48]. Noteworthy, the BCR-ABL fusion protein activates emergency granulopoiesis by upregulating $\mathrm{C} / \mathrm{EBP} \beta$, which in turn might support chronic myeloid leukemia [49].

Terminal macrophage differentiation is instead induced by M-CSF through activation of the transcription factors PU.1 and IRF8 [50]. We have recently shown that myeloidspecific expression of RORC1/RORY marks advanced cancer stages [26] and orchestrates emergency myelopoiesis by suppressing negative (Socs 3 and $\mathrm{Bcl} 3$ ) and promoting positive $(C / E B P \beta)$ regulators of granulopoiesis, as well as the key transcriptional mediators of myeloid progenitor commitment and differentiation to the monocytic/macrophage lineage (IRF8 and PU.1). Interestingly, IRF8 also functions as a "master" negative regulator of MDSC generation[51]. This plastic commitment of myeloid progenitors is further highlighted by the observation that, via HIF-1 $\alpha$ activation, hypoxia redirects the differentiation of MDSCs toward tumor-associated macrophages, hence providing a mechanistic link between different myeloid suppressive cells in the tumor microenvironment [31].

Epigenetic modifications are also important regulators of myeloid cell functions. Recent studies demonstrate that chromatin-modifying enzymes could sense the macrophage's metabolic status (i.e. availability of acetylcoenzyme A, S-adenosylmethionine, $\alpha$-ketoglutarate ( $\alpha K G$ ), nicotinamide adenine dinucleotide and polyamines) to promote their transcriptional reprogramming and phenotypic changes [52]. Of relevance, Liu PS et al. recently demonstrated that $\alpha$ KG produced by glutaminolysis is an 


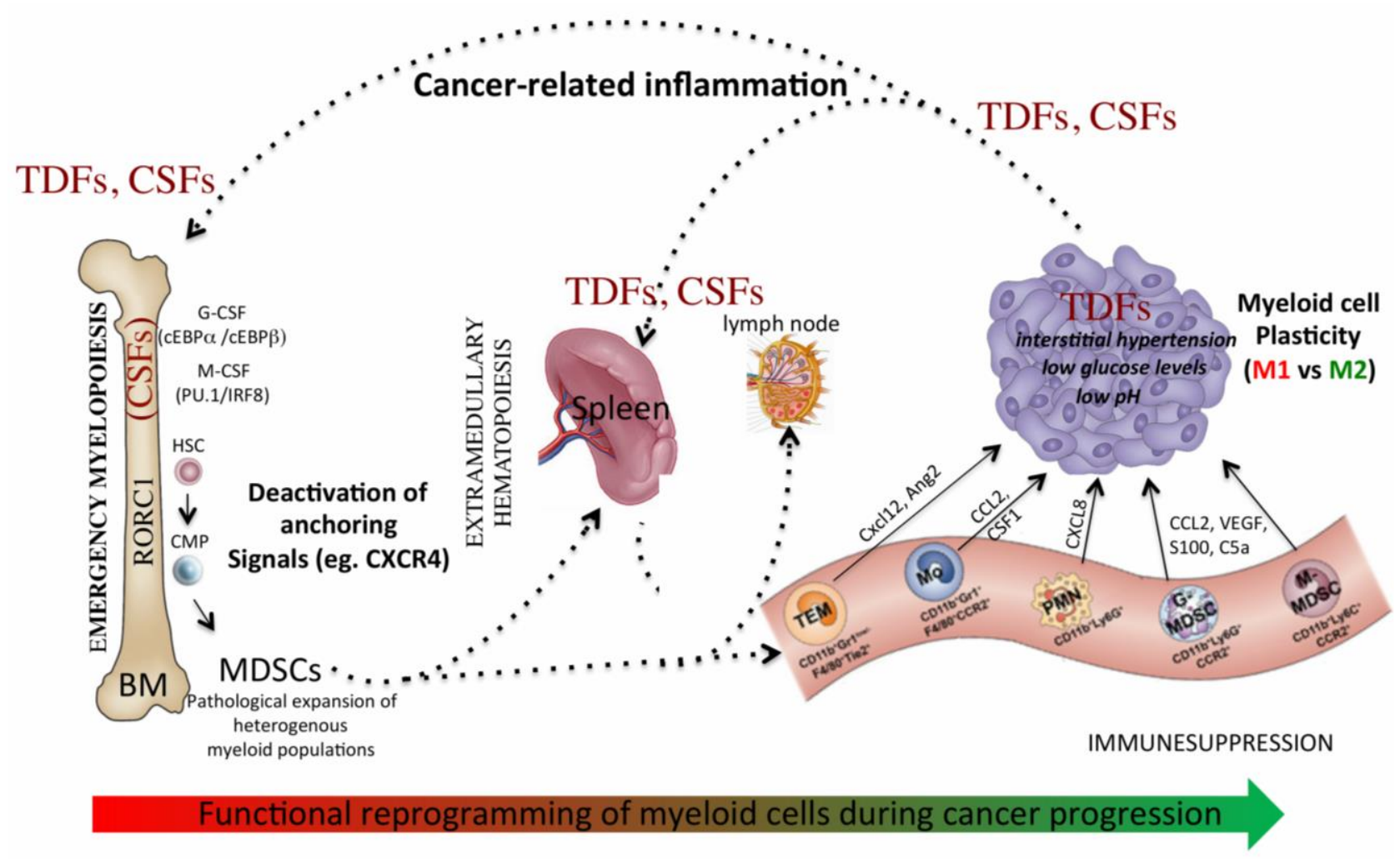

FIGURE 1: Myeloid cell reprogramming in cancer: a dynamic multistep process. Cancer-related inflammation promotes emergency myelopoiesis through production of colony stimulating factors, such as macrophage-colony stimulating factor (M-CSF), granulocyte-colony stimulating factor (G-CSF), granulocyte-macrophage- colony stimulating factor (GM-CSF). The transcription factor RORC1 is a key mediator of this myelopoietic response in emergency. Deactivation of anchoring signals, such as the retention axis CXCR4/CXCL12 promotes mobilization of myeloid cells to periphery and allows their accumulation to lymphoid organs, as well tumor tissues. Recruitment of myeloid cells into the tumor microenvironment expose these cells to additional signals and conditions that further boost their functional reprogramming towards a tumor-promoting phenotype. CSFs - Colony-stimulating factors, TDFs - tumor-derived factors, TEM - TIE2-expressing monocytes, PMN - polymorphonuclear cells, Mo - monocytes, MDSCs - myeloid-derived suppressor cells.

anti-inflammatory metabolite that augments $\mathrm{M} 2$ activation and controls metabolic reprogramming of $\mathrm{M} 2$ macrophages through the Jumonji domain containing-3 (Jmjd3)dependent regulations [53]. Furthermore, epigenetic silencing of the retinoblastoma gene operated by histone deacetylase 2 (HDAC-2) drives the transdifferentiation of M-MDSCs into PMN-MDSCs in cancer [54].

\section{HOST METABOLISM AND MYELOPOIESIS}

HSCs are mainly found in secured niches in the BM and are programmed for enforced quiescence. This "dormancy state" allows adult HSCs to be ready for quick and massive production of blood cells under emergency conditions, while limiting their proliferation to routinely production of blood cells. Therefore, under normal conditions, adult HSCs divide rarely to maintain low production of committed progenitor cells and refill the HSCs pool. However, they can rapidly and transiently proliferate in response to many inflammatory signals [55] such as acute infection, becoming rapidly activated for terminal differentiation and functional maturation, to exert their specialized immune functions against pathogens. Understanding how hematopoie- sis is altered upon environmental stress is currently a major focus of research [56], addressed in preclinical models challenged with hematopoietic stresses such as infection or chronic inflammation. This metabolic influence has been extensively studied also under conditions of altered host metabolism, such as in the obese patients $[57,58]$. Indeed, obesity-induced chronic inflammation is a key component in the pathogenesis of both insulin resistance and metabolic syndrome and is characterized by continuous production of proinflammatory cytokines that can lead to significant alteration in HSCs function and output $[15,59]$. In difference to acute inflammatory stress, inducing a response that is quickly suppressed upon restoration of tissue homeostasis, failure to efficiently resolve inflammatory insults can have serious consequences for tissue maintenance and function. Indeed, in the context of chronic inflammation due to metabolic diseases such as obesity and type 2 diabetes, the inflammatory stress fails to resolve, leading to a persistent inflammatory state $[15,59]$.

Obesity, in fact, leads to a chronic inflammatory phenotype favoring the infiltration of activated immune cells into the adipose tissue and can be considered as a chronic pathological state associated with BM stresses [60]. In par- 
allel, diabetes adversely impacts the mobilization capacity of HSCs by altering chemokine expression in the BM niche [61].

Of note, impaired blood system function is a common feature of these conditions, characterized by cytopenia in one or more lineages, anemia, thrombocytosis, suppression of lymphopoiesis, overproduction of myeloid cell populations that mediate further damage, or suppression of BM function [56, 62]. These data support the hypothesis that the enforced quiescence status prevents HSCs depletion during disease-induced chronic inflammation and suggest that the multipotent progenitor (MPP) compartment, which is responsible for everyday blood maintenance, may compensate ongoing needs, minimizing continued HSCS proliferation. In this perspective, it might also be considered that HSCs exhibit a finite replicative potential and chronic inflammation, or serial inflammatory episodes that induce HSCs proliferation, may create a maladaptive context, leading to HSCs decline and BM niche dysfunction. These findings have indeed raised new questions on the different impacts of inflammation on HSCs fate and function. The presence of a chronic inflammatory status associated with insulin resistance has also been linked with a higher risk of developing several types of cancer [63] by a number of epidemiological studies.

This association is biologically plausible as hyperinsulinemia induces proliferative tissue abnormalities due to the strong anabolic effect of insulin, resulting in the enhancement of DNA synthesis and cell proliferation. Furthermore, in patients with breast cancer (BC), higher circulating insulin levels have been found to be associated with an adverse outcome [64]. Recent evidence also indicates that the presence of insulin resistance is associated with a significantly worse prognosis in patients with advanced BC treated with chemotherapy [65]. Obesity itself has been hypothesized to impact response to chemotherapy, not only through metabolic perturbations such as the underlying insulin resistance status, hyperglycemia, adpokine production, and insulin-like growth factor (IGF)-1 system, but also affecting drug delivery, pharmacokinetics and transport. However, epidemiological studies in patients treated with chemotherapy have produced inconsistent results, with some showing an adverse effect and others a protective effect [66].

In cancer patients hematopoiesis is characterized by an increase in myeloid differentiation, which is believed to give an important contribution to the establishment of an immunosuppressive environment [67]. This is mainly due to the accumulation of MDSCs, that suppress adaptive immunity favoring cancer cell proliferation, tumor growth and survival, angiogenesis and metastasis. Under this hypothesis, the relationship between insulin resistance, obesity, metabolic impairment, with the underlying chronic inflammatory status and cancer needs to be extensively evaluated and approached in a multidisciplinary fashion. Indeed, the recent evidence [68] that patients with a higher Body Mass Index (i.e. overweight or obese) have an improved outcome if treated with immunotherapy for advanced tumors [69], indicates that the immune system, its targeting by cancer immunotherapy and patient metabolic status are closely connected. It is therefore critical to understand the potential effects of metabolic impairment on cancer related immunity, to improve treatment outcome with immuno-targeting.

\section{CELL METABOLISM AND MYELOPOIESIS}

The relationship between metabolic alterations and the tumor-promoting functions of myeloid cells is further emerging as a crucial aspect of TAMs and MDSCs skewing toward pro-tumoral activities and their metabolic reeducation appears as a new strategy to boost antitumor effector functions [15]. Within this scenario, the use of pharmacological agents to manipulate cell metabolism is an important step forward in the development of clinically relevant strategies. As an example, metabolites and metabolic regulators such as lactic acid, HIF1, c-Myc, adenosine monophosphate kinase (AMPK), and mTOR, which control metabolic reprogramming of immune cells and tumor cells, are being tested for targeting. Drugs targeting the lactate transporters MCT1 and MCT2 [70] and AMPK (e.g., metformin) are being evaluated for anti-tumor effects in preclinical models and in clinical trials [71].

Interestingly, besides affecting tumor cells, metformin has a direct effect on infiltrating immune cells: increasing $\mathrm{CD}^{+} \mathrm{T}$ cell recruitment, protecting them from apoptosis and exhaustion, increasing $\mathrm{CD}^{+}$memory $\mathrm{T}$ cells and providing a better response to anti-cancer vaccines [59]. Moreover, accumulating evidences indicate that AMPK, which is a central regulator of fatty acid, cholesterol, and glucose homeostasis, also skews macrophages polarization towards the M2 phenotype. More recently it was shown that in MDSCs, PPARY plays a critical role in neutral lipid metabolism signaling controlled by lysosomal acid lipase (LAL) and that enhanced PPARY activity impairs MDSCsmediated proliferation and spreading of cancer cells [72]. Of note, both mouse and human tumor-infiltrating MDSCs, which accumulate during cancer progression, show a preferential increase of fatty acid uptake and fatty acid oxidation over glycolysis [73]. This metabolic profile is shared by $\mathrm{M}$ - and PMN-MDSCs subsets and dictates their immunosuppressive behavior inside the tumor [73]. Further, upregulation of fatty-acid synthase (FASN) by M-CSF in tumor infiltrating myeloid cells was required for PPAR $\beta / \delta$ dependent expression of immunosuppressive and proangiogenic genes (e.g. IL-10, Arg1 and VEGF) and consequent promotion of tumor progression [74], in a model of Lewis lung cancer.

In this perspective, the antitumor effect of metformin was recently evaluated in two prospective, randomized trials, in non-diabetic women affected by early and advanced $B C$. The first one was a window of opportunity, double-blind, randomized study in early BC patients, candidate to surgery: in this setting, the administration of metformin single agent for four weeks before surgery, did not impact tumor proliferation, compared to baseline levels, in the overall patient population. However, a significant effect was seen in insulin-resistant patients [75]. In the met- 
astatic setting, the addition of metformin to first-line chemotherapy as compared to chemotherapy alone, did not improve progression free survival or overall survival. Of note, patients receiving the combination of metformin and chemotherapy experienced significantly lower severe neutropenia as compared to chemotherapy alone, suggesting a protective effect on BM toxicity [65]. A large adjuvant trial on non-diabetic women with early $\mathrm{BC}$ comparing metformin with matching placebo in terms of disease-free survival (DFS) is currently ongoing.

\section{CHEMOTHERAPY EFFECTS ON MYELOPOIESIS AND IMPLICATION FOR IMMUNOTHERAPY}

Malignant transformation and progression cannot occur without the aid of host-derived factors. The interplay among tumor cells, stroma and immune system cells contributes to the shaping of tumor microenvironment where reprogrammed non-cancer cells sustain angiogenesis, cell growth, diversion and skewing of adaptive response. As previously discussed, the myeloid compartment plays a key role in this tumor reconditioning, which results in the generation of myeloid cells with special immunosuppressive properties. Of note, atypical myelopoiesis has also been described in hematologic malignancies including multiple myeloma, leukemias and lymphomas. In this perspective, acute and chronic myeloid leukemia can be considered the most extreme examples of deregulated myelopoiesis [76].

Chemotherapy represents an important component of the therapeutic armamentarium against cancer. More recently, restoring immune response with immune checkpoint inhibitors has emerged as an efficient treatment for several cancer types. Even though apparently counterproductive, the combination of these two strategies resulted in clinically meaningful results [77-79]. Indeed, chemotherapy has been historically viewed as immunosuppressive mainly because of its lymphodepleting effect. However, chemotherapy effects on the immune system are extremely complex. Most preclinical studies support chemotherapy-induced inflammation as a mechanism to reinforce aberrant myelopoiesis, through the generation and expansion of MDSCs. This effect is suggested as a counter-regulatory adaptation to prevent unnecessary damage from a chemical insult [80]. Enhancement of MDSCs suppressive activity is described with doxorubicin and with high-dose cyclophosphamide, among others [81]. In contrast, other preclinical data have shown that a number of cytotoxic agents, such as gemcitabine, docetaxel and 5-fluorouracil, can induce MDSCs apoptosis [82-84]. Cyclophosphamide can be considered the paradigm of the complexity of the interplay between chemotherapy and the immune system, since both immuno-stimulating effects as well as induction of immunosuppressive cells have been described with this cytotoxic agent [85]. Indeed, MDSCs accumulation was reported by several authors $[86,87]$. However, when administered at low dose, cyclophosphamide causes Treg cell depletion, augmenting antitumor response and increasing expression of DC maturation markers [88, 89]. Data from clinical studies prospectively evaluating the effects of chemotherapy on MDSCs are scanty, and the results somewhat conflicting. Diaz et al. [90] evaluated 17 stage IIIII BC patients treated with adjuvant dose-dense doxorubicin-cyclophosphamide (AC) followed by dose dense paclitaxel [91]. A significant increase in MDSCs was described after dose-dense AC. More recently, in 24 BC patients undergoing neoadjuvant sequential chemotherapy, a significant increase in granulocytic-MDSC was reported after AC therapy, with subsequent decrease to near baseline levels during paclitaxel treatment [90]. PMN-MDSCs levels at the last draw were numerically lower in patients with pathologic complete responses ( $p C R s$ ) versus patients with no pCR. However, these data are far from being conclusive, considering the limited sample size, the inclusion of heterogeneous patient population with respect to hormone receptor and HER2 expression, as well as the use of G-CSF. Indeed, G-CSF is one of the key drivers of aberrant expansion of myeloid cells, and the common use of exogenous G-CSF in cancer patients undergoing chemotherapy might play a role in the immunosuppressive status induced by the tumor. The largest study so far included 56 patients with locally advanced $B C$ undergoing neoadjuvant therapy with sequential $A C$ followed by docetaxel+/- capecitabine [92]. In contrast to the findings of the other two trials, monocytic and granulocytic MDSCs were significantly reduced after both four and eight courses of chemotherapy, irrespective of response. Interestingly, circulatory levels of Treg were significantly associated with pathologic response.

In patients with non-small cell lung cancer treated with first-line platinum-based chemotherapy, higher M-MDSCs significantly correlated with worse outcome. However, dynamic changes of MDSCs during chemotherapy were not evaluated [93]. In 23 patients with advanced colorectal cancer, decreased levels of MDSCs were observed after therapy with 5-fluorouracil combined with oxaliplatin (FOLFOX), while persistent increase of MDSCs was reported after 5-fluorouracil combined with Irinotecan (FOLFIRI) [94]. As a whole, these data suggest that chemotherapy can impact on the tumor microenvironment by promoting antitumor immune response, or by inducing MDSCs that counter-regulate immune response.

Immunotherapy is now established as a groundbreaking strategy in several tumors; however, a significant proportion of patients does not respond or even experience hyperprogression. Taking into account the costs, as well as the potential side effects of these treatments, adequate patient selection is highly needed. Tissue biomarkers are promising, but not suitable for dynamic evaluation. In this context, circulating immune-related biomarkers are particularly attractive. Peripheral blood mononuclear cells phenotyping is considered a dynamic marker to evaluate pre-existing immunity that could affect outcome and sensitivity to treatments. MDSCs levels have been associated with prognosis in ipilimumab-treated patients. In particular, on-treatment high levels of $\mathrm{CD} 14^{+} /$IL $4 R \alpha^{+}$MDSCs were negative independent factors of reduced overall survival in a cohort of melanoma patients treated with ipilimumab [95]. 
Prospective MDSCs and TAMs evaluation in trials of chemo-immunotherapy could elucidate the mechanisms underlying different tumor behaviors upon treatment exposure. Moreover, identifying the drivers of treatment resistance can be helpful to select potential targets to restore antitumor immune response.

\section{CONCLUSIONS}

Solid tumors are composed by cancer cells, stroma and a variety of infiltrating immune cells, which establish reciprocal relationships that dictate the clinical outcome. Despite this evidence, the mechanisms leading to accumulation of tumor-promoting myeloid cells in the tumor microenvironment are far from being understood, though might likely be the sum of sequential alterations targeting: differentiation of myeloid progenitors and their mobilization to periphery; their recruitment to both secondary lymphoid organs and tumor tissues; their functional diversion in response to microenvironmental signals and conditions. Efforts are being made to characterize the immunostimulatory properties of chemotherapeutic agents and how they can be best combined with immune checkpoint inhibitors and new evidence indicates that chemotherapeutics (e.g. paclitaxel acting as TLR4 agonist) [96] can restore the anticancer activity of TAMs and improve the clinical efficacy of immune checkpoint inhibitors. In this perspective, while the tumor microenvironment has been considered as a suitable target for therapeutic interventions, new studies should carefully evaluate the impact of therapies on the quality and extent of the hematopoietic response, aiming to differentially target multiple levels of the tumorpromoting reprogramming of myeloid cells. The analysis of the effects and mechanisms elicited by different chemotherapeutics, dose and timing of administration, as well as their interplay with metabolic traits, seems therefore crucial to establish the drivers of myelopoietic alterations associated with tumor progression and for a correct stratification of patients, in order to achieve a rational combination that can activate synergism between chemotherapy and immunotherapy.

\section{ACKNOWLEDGMENTS}

This work was supported by the Italian Association for Cancer Research (AIRC projects IG 19885 and AIRC 5x1000 project 22757); Fondazione Cariplo, Italy; Italian Ministry of Education, Universities and Research, Italy (MIUR; grant numbers 2015YYKPNN_004 and 2017BA9LM5).

\section{CONFLICT OF INTEREST}

There is no conflict of interest.

\section{COPYRIGHT}

(C) 2019 Sica et al. This is an open-access article released under the terms of the Creative Commons Attribution (CC BY) license, which allows the unrestricted use, distribution, and reproduction in any medium, provided the original author and source are acknowledged.

Please cite this article as: Antonio Sica, Valentina Guarneri and Alessandra Gennari (2019). Myelopoiesis, metabolism and therapy: a crucial crossroads in cancer progression. Cell Stress 3(9): 284-294. doi: 10.15698/cst2019.09.197

7. Janeway CA, Jr. (1989). Approaching the asymptote? Evolution and revolution in immunology. Cold Spring Harb Symp Quant Biol 54 (Pt 1): 1-13. doi: 10.1101/sqb.1989.054.01.003

8. Escamilla-Tilch M, Filio-Rodriguez G, Garcia-Rocha R, MancillaHerrera I, Mitchison NA, Ruiz-Pacheco JA, Sanchez-Garcia FJ, Sandoval-Borrego D, Vazquez-Sanchez EA (2013). The interplay between pathogen-associated and danger-associated molecular patterns: an inflammatory code in cancer? Immunol Cell Biol 91(10): 601-610. doi: 10.1038/icb.2013.58

9. Liu B, Tan W, Barsoum A, Gu X, Chen K, Huang W, Ramsay A, Kolls JK, Schwarzenberger $P$ (2010). IL-17 is a potent synergistic factor with GM-CSF in mice in stimulating myelopoiesis, dendritic cell expansion, proliferation, and functional enhancement. Exp Hematol 38(10): 877 884 e871. doi: 10.1016/j.exphem.2010.06.004

10. Schwarzenberger $P$, Huang $W$, Ye $P$, Oliver $P$, Manuel $M$, Zhang $Z$, Bagby G, Nelson S, Kolls JK (2000). Requirement of endogenous stem cell factor and granulocyte-colony-stimulating factor for IL-17mediated granulopoiesis. J Immunol 164(9): 4783-4789. doi: 10.4049/jimmunol.164.9.4783

11. Pietras EM, Mirantes-Barbeito C, Fong S, Loeffler D, Kovtonyuk LV, Zhang S, Lakshminarasimhan R, Chin CP, Techner JM, Will B, Nerlov C, Steidl U, Manz MG, Schroeder T, Passegue E (2016). Chronic interleukin-1 exposure drives haematopoietic stem cells towards
6. Fridlender ZG, Sun J, Kim S, Kapoor V, Cheng G, Ling L, Worthen GS Albelda SM (2009). Polarization of tumor-associated neutrophil phenotype by TGF-beta: "N1" versus "N2" TAN. Cancer Cell 16(3): 183-194. doi: 10.1016/j.ccr.2009.06.017 
precocious myeloid differentiation at the expense of self-renewal. Nat Cell Biol 18(6): 607-618. doi: 10.1038/ncb3346

12. Bernad A, Kopf M, Kulbacki R, Weich N, Koehler G, GutierrezRamos JC (1994). Interleukin-6 is required in vivo for the regulation of stem cells and committed progenitors of the hematopoietic system. Immunity 1(9): 725-731. doi: 10.1016/s1074-7613(94)80014-6

13. Patchen ML, MacVittie TJ, Williams JL, Schwartz GN, Souza LM (1991). Administration of interleukin-6 stimulates multilineage hematopoiesis and accelerates recovery from radiation-induced hematopoietic depression. Blood 77(3): 472-480. PMID: 1991164

14. Kuderer NM, Dale DC, Crawford J, Cosler LE, Lyman GH (2006). Mortality, morbidity, and cost associated with febrile neutropenia in adult cancer patients. Cancer 106(10): 2258-2266. doi: 10.1002/cncr.21847

15. Porta C, Marino A, Consonni FM, Bleve A, Mola S, Storto M, Riboldi $E$, Sica A (2018). Metabolic influence on the differentiation of suppressive myeloid cells in cancer. Carcinogenesis 39(9): 1095-1104. doi: $10.1093 /$ carcin/bgy088

16. Medina E, Hartl D (2018). Myeloid-Derived Suppressor Cells in Infection: A General Overview. J Innate Immun 10(5-6): 407-413. doi: $10.1159 / 000489830$

17. Bronte V, Brandau S, Chen SH, Colombo MP, Frey AB, Greten TF, Mandruzzato S, Murray PJ, Ochoa A, Ostrand-Rosenberg S, Rodriguez PC, Sica A, Umansky V, Vonderheide RH, Gabrilovich DI (2016). Recommendations for myeloid-derived suppressor cell nomenclature and characterization standards. Nat Commun 7: 12150. doi: 10.1038/ncomms12150

18. Weber R, Fleming V, Hu X, Nagibin V, Groth C, Altevogt P, Utikal J, Umansky V (2018). Myeloid-Derived Suppressor Cells Hinder the AntiCancer Activity of Immune Checkpoint Inhibitors. Front Immunol 9: 1310. doi: 10.3389/fimmu.2018.01310

19. Mantovani A, Marchesi F, Malesci A, Laghi L, Allavena P (2017). Tumour-associated macrophages as treatment targets in oncology. Nat Rev Clin Oncol 14(7): 399-416. doi: 10.1038/nrclinonc.2016.217

20. Sica A, Mantovani A (2012). Macrophage plasticity and polarization: in vivo veritas. J Clin Invest 122(3): 787-795. doi: $10.1172 / \mathrm{JCl} 59643$

21. Tcyganov E, Mastio J, Chen E, Gabrilovich DI (2018). Plasticity of myeloid-derived suppressor cells in cancer. Curr Opin Immunol 51: 76-82. doi: 10.1016/j.coi.2018.03.009

22. Murray PJ, Allen JE, Biswas SK, Fisher EA, Gilroy DW, Goerdt S, Gordon S, Hamilton JA, Ivashkiv LB, Lawrence T, Locati M, Mantovani A, Martinez FO, Mege JL, Mosser DM, Natoli G, Saeij JP, Schultze JL, Shirey KA, Sica A, Suttles J, Udalova I, van Ginderachter JA, Vogel SN, Wynn TA (2014). Macrophage activation and polarization: nomenclature and experimental guidelines. Immunity 41(1): 14-20. doi: 10.1016/j.immuni.2014.06.008

23. Movahedi K, Laoui D, Gysemans C, Baeten M, Stange G, Van den Bossche J, Mack M, Pipeleers D, In't Veld P, De Baetselier P, Van Ginderachter JA (2010). Different tumor microenvironments contain functionally distinct subsets of macrophages derived from Ly6C(high) monocytes. Cancer Res 70(14): 5728-5739. doi: 10.1158/00085472.CAN-09-4672

24. Coffelt SB, Wellenstein MD, de Visser KE (2016). Neutrophils in cancer: neutral no more. Nat Rev Cancer 16(7): 431-446. doi: $10.1038 /$ nrc. 2016.52

25. Mantovani A, Allavena P, Sica A, Balkwill F (2008). Cancer-related inflammation. Nature 454(7203): 436-444. doi: 10.1038/nature07205

26. Strauss L, Sangaletti S, Consonni FM, Szebeni G, Morlacchi S, Totaro MG, Porta C, Anselmo A, Tartari S, Doni A, Zitelli F, Tripodo C,
Colombo MP, Sica A (2015). RORC1 Regulates Tumor-Promoting "Emergency" Granulo-Monocytopoiesis. Cancer Cell 28(2): 253-269. doi: 10.1016/j.ccell.2015.07.006

27. Travelli C, Consonni FM, Sangaletti S, Storto M, Morlacchi S, Grolla AA, Galli U, Tron GC, Portararo P, Rimassa L, Pressiani T, Mazzone M, Trovato R, Ugel S, Bronte V, Tripodo C, Colombo MP, Genazzani AA Sica A (2019). Nicotinamide Phosphoribosyltransferase Acts as a Metabolic Gate for Mobilization of Myeloid-Derived Suppressor Cells. Cancer Res doi: 10.1158/0008-5472.CAN-18-1544

28. Qian BZ, Li J, Zhang H, Kitamura T, Zhang J, Campion LR, Kaiser EA, Snyder LA, Pollard JW (2011). CCL2 recruits inflammatory monocytes to facilitate breast-tumour metastasis. Nature 475(7355): 222-225. doi: $10.1038 /$ nature10138

29. Schioppa T, Uranchimeg B, Saccani A, Biswas SK, Doni A, Rapisarda A, Bernasconi S, Saccani S, Nebuloni M, Vago L, Mantovani A, Melillo G, Sica A (2003). Regulation of the chemokine receptor CXCR4 by hypoxia. J Exp Med 198(9): 1391-1402. doi: 10.1084/jem.20030267

30. Colegio OR, Chu NQ, Szabo AL, Chu T, Rhebergen AM, Jairam V, Cyrus N, Brokowski CE, Eisenbarth SC, Phillips GM, Cline GW, Phillips AJ, Medzhitov R (2014). Functional polarization of tumour-associated macrophages by tumour-derived lactic acid. Nature 513(7519): 559563. doi: $10.1038 /$ nature 13490

31. Corzo CA, Condamine T, Lu L, Cotter MJ, Youn JI, Cheng P, Cho HI, Celis E, Quiceno DG, Padhya T, McCaffrey TV, McCaffrey JC, Gabrilovich DI (2010). HIF-1alpha regulates function and differentiation of myeloid-derived suppressor cells in the tumor microenvironment. J Exp Med 207(11): 2439-2453. doi: 10.1084/jem.20100587

32. Pearce EJ, Everts B (2015). Dendritic cell metabolism. Nat Rev Immunol 15(1): 18-29. doi: 10.1038/nri3771

33. Yang L, Carbone DP (2004). Tumor-host immune interactions and dendritic cell dysfunction. Adv Cancer Res 92: 13-27. doi: 10.1016/S0065-230X(04)92002-7

34. Oguro H, McDonald JG, Zhao Z, Umetani M, Shaul PW, Morrison SJ (2017). 27-Hydroxycholesterol induces hematopoietic stem cell mobilization and extramedullary hematopoiesis during pregnancy. J Clin Invest 127(9): 3392-3401. doi: 10.1172/JCI94027

35. Traversari C, Sozzani S, Steffensen KR, Russo V (2014). LXRdependent and -independent effects of oxysterols on immunity and tumor growth. Eur J Immunol 44(7): 1896-1903. doi: 10.1002/eji.201344292

36. Bensinger SJ, Tontonoz $\mathrm{P}$ (2008). Integration of metabolism and inflammation by lipid-activated nuclear receptors. Nature 454(7203): 470-477. doi: 10.1038/nature07202

37. Villablanca EJ, Raccosta L, Zhou D, Fontana R, Maggioni D, Negro A, Sanvito F, Ponzoni M, Valentinis B, Bregni M, Prinetti A, Steffensen KR, Sonnino S, Gustafsson JA, Doglioni C, Bordignon C, Traversari C, Russo $V$ (2010). Tumor-mediated liver $X$ receptor-alpha activation inhibits CC chemokine receptor-7 expression on dendritic cells and dampens antitumor responses. Nat Med 16(1): 98-105. doi: 10.1038/nm.2074

38. Nguyen NT, Kimura A, Nakahama T, Chinen I, Masuda K, Nohara K, Fujii-Kuriyama $Y$, Kishimoto $T$ (2010). Aryl hydrocarbon receptor negatively regulates dendritic cell immunogenicity via a kynureninedependent mechanism. Proc Natl Acad Sci U S A 107(46): 1996119966. doi: 10.1073/pnas.1014465107

39. Viaud S, Saccheri F, Mignot G, Yamazaki T, Daillere R, Hannani D, Enot DP, Pfirschke C, Engblom C, Pittet MJ, Schlitzer A, Ginhoux F, Apetoh L, Chachaty E, Woerther PL, Eberl G, Berard M, Ecobichon C, Clermont D, Bizet C, Gaboriau-Routhiau V, Cerf-Bensussan N, Opolon P, Yessaad N, Vivier E, Ryffel B, Elson CO, Dore J, Kroemer G, Lepage P, 
et al. (2013). The intestinal microbiota modulates the anticancer immune effects of cyclophosphamide. Science 342(6161): 971-976. doi: 10.1126/science.1240537

40. Vetizou M, Pitt JM, Daillere R, Lepage $P$, Waldschmitt N, Flament C, Rusakiewicz S, Routy B, Roberti MP, Duong CP, Poirier-Colame V, Roux A, Becharef S, Formenti S, Golden E, Cording S, Eberl G, Schlitzer A, Ginhoux F, Mani S, Yamazaki T, Jacquelot $N$, Enot DP, Berard $M$, Nigou J, Opolon P, Eggermont A, Woerther PL, Chachaty E, Chaput N, et al. (2015). Anticancer immunotherapy by CTLA-4 blockade relies on the gut microbiota. Science 350(6264): 1079-1084. doi: 10.1126/science.aad1329

41. Gopalakrishnan V, Spencer CN, Nezi L, Reuben A, Andrews MC, Karpinets TV, Prieto PA, Vicente D, Hoffman K, Wei SC, Cogdill AP, Zhao L, Hudgens CW, Hutchinson DS, Manzo T, Petaccia de Macedo M, Cotechini T, Kumar T, Chen WS, Reddy SM, Szczepaniak Sloane R, Galloway-Pena J, Jiang H, Chen PL, Shpall EJ, Rezvani K, Alousi AM, Chemaly RF, Shelburne S, Vence LM, et al. (2018). Gut microbiome modulates response to anti-PD-1 immunotherapy in melanoma patients. Science 359(6371): 97-103. doi: 10.1126/science.aan4236

42. Ramakrishnan R, Tyurin VA, Veglia F, Condamine T, Amoscato A, Mohammadyani D, Johnson JJ, Zhang LM, Klein-Seetharaman J, Celis E, Kagan VE, Gabrilovich DI (2014). Oxidized lipids block antigen crosspresentation by dendritic cells in cancer. J Immunol 192(6): 29202931. doi: 10.4049/jimmunol.1302801

43. Gottfried E, Kunz-Schughart LA, Ebner S, Mueller-Klieser W, Hoves $\mathrm{S}$, Andreesen R, Mackensen A, Kreutz M (2006). Tumor-derived lactic acid modulates dendritic cell activation and antigen expression. Blood 107(5): 2013-2021. doi: 10.1182/blood-2005-05-1795

44. Hirai $H$, Zhang $P$, Dayaram $T$, Hetherington CJ, Mizuno S, Imanishi J, Akashi K, Tenen DG (2006). C/EBPbeta is required for 'emergency' granulopoiesis. Nat Immunol 7(7): 732-739. doi: 10.1038/ni1354

45. Akagi T, Saitoh T, O'Kelly J, Akira S, Gombart AF, Koeffler HP (2008). Impaired response to GM-CSF and G-CSF, and enhanced apoptosis in C/EBPbeta-deficient hematopoietic cells. Blood 111(6): 2999-3004. doi: 10.1182/blood-2007-04-087213

46. Zhang H, Nguyen-Jackson H, Panopoulos AD, Li HS, Murray PJ, Watowich SS (2010). STAT3 controls myeloid progenitor growth during emergency granulopoiesis. Blood 116(14): 2462-2471. doi: 10.1182/blood-2009-12-259630

47. Wang D, Paz-Priel I, Friedman AD (2009). NF-kappa B p50 regulates $\mathrm{C} / \mathrm{EBP}$ alpha expression and inflammatory cytokine-induced neutrophil production. J Immunol 182(9): 5757-5762. doi: 10.4049/jimmunol.0803861

48. Marigo I, Bosio E, Solito S, Mesa C, Fernandez A, Dolcetti L, Ugel S, Sonda N, Bicciato S, Falisi E, Calabrese F, Basso G, Zanovello P, Cozzi E, Mandruzzato S, Bronte V (2010). Tumor-induced tolerance and immune suppression depend on the C/EBPbeta transcription factor. Immunity 32(6): 790-802. doi: 10.1016/j.immuni.2010.05.010

49. Hirai H, Yokota A, Tamura A, Sato A, Maekawa T (2015). Nonsteady-state hematopoiesis regulated by the C/EBPbeta transcription factor. Cancer Sci 106(7): 797-802. doi: 10.1111/cas.12690

50. Friedman AD (2007). Transcriptional control of granulocyte and monocyte development. Oncogene 26(47): 6816-6828. doi: 10.1038/sj.onc. 1210764

51. Waight JD, Netherby C, Hensen ML, Miller A, Hu Q, Liu S, Bogner PN, Farren MR, Lee KP, Liu K, Abrams SI (2013). Myeloid-derived suppressor cell development is regulated by a STAT/IRF-8 axis. J Clin Invest 123(10): 4464-4478. doi: 10.1172/JCI68189

52. Baardman J, Licht I, de Winther MP, Van den Bossche J (2015). Metabolic-epigenetic crosstalk in macrophage activation. Epigenomics 7(7): 1155-1164. doi: 10.2217/epi.15.71
53. Liu PS, Wang H, Li X, Chao T, Teav T, Christen S, Di Conza G, Cheng WC, Chou CH, Vavakova M, Muret C, Debackere K, Mazzone M, Huang HD, Fendt SM, Ivanisevic J, Ho PC (2017). alpha-ketoglutarate orchestrates macrophage activation through metabolic and epigenetic reprogramming. Nat Immunol 18(9): 985-994. doi: 10.1038/ni.3796

54. Youn JI, Kumar V, Collazo M, Nefedova $Y$, Condamine $T$, Cheng $P$, Villagra A, Antonia S, McCaffrey JC, Fishman M, Sarnaik A, Horna P, Sotomayor E, Gabrilovich DI (2013). Epigenetic silencing of retinoblastoma gene regulates pathologic differentiation of myeloid cells in cancer. Nat Immunol 14(3): 211-220. doi: 10.1038/ni.2526

55. Chiba $Y$, Mizoguchi I, Hasegawa $H$, Ohashi M, Orii N, Nagai T, Sugahara M, Miyamoto Y, Xu M, Owaki T, Yoshimoto T (2018). Regulation of myelopoiesis by proinflammatory cytokines in infectious diseases. Cell Mol Life Sci 75(8): 1363-1376. doi: 10.1007/s00018-0172724-5

56. Pietras EM (2017). Inflammation: a key regulator of hematopoietic stem cell fate in health and disease. Blood 130(15): 1693-1698. doi: 10.1182/blood-2017-06-780882

57. de Luca C, Olefsky JM (2008). Inflammation and insulin resistance. FEBS Lett 582(1): 97-105. doi: 10.1016/j.febslet.2007.11.057

58. Bao Y, Mo J, Ruan L, Li G (2015). Increased monocytic CD14(+)HLADRlow/- myeloid-derived suppressor cells in obesity. Mol Med Rep 11(3): 2322-2328. doi: 10.3892/mmr.2014.2927

59. Deng T, Lyon CJ, Bergin S, Caligiuri MA, Hsueh WA (2016). Obesity, Inflammation, and Cancer. Annu Rev Pathol 11: 421-449. doi: 10.1146/annurev-pathol-012615-044359

60. Lee JM, Govindarajah V, Goddard B, Hinge A, Muench DE, Filippi MD, Aronow B, Cancelas JA, Salomonis N, Grimes HL, Reynaud D (2018). Obesity alters the long-term fitness of the hematopoietic stem cell compartment through modulation of Gfil expression. J Exp Med 215(2): 627-644. doi: 10.1084/jem.20170690

61. Ferraro F, Lymperi S, Mendez-Ferrer S, Saez B, Spencer JA, Yeap BY, Masselli E, Graiani G, Prezioso L, Rizzini EL, Mangoni M, Rizzoli V, Sykes SM, Lin CP, Frenette PS, Quaini F, Scadden DT (2011). Diabetes impairs hematopoietic stem cell mobilization by altering niche function. Sci Transl Med 3(104): 104ra101. doi: 10.1126/scitranslmed.3002191

62. Penaloza HF, Alvarez D, Munoz-Durango N, Schultz BM, Gonzalez PA, Kalergis AM, Bueno SM (2018). The role of myeloid-derived suppressor cells in chronic infectious diseases and the current methodology available for their study. J Leukoc Biol doi: 10.1002/JLB.MR0618-233R

63. Cowey S, Hardy RW (2006). The metabolic syndrome: A high-risk state for cancer? Am J Pathol 169(5): 1505-1522. doi: 10.2353/ajpath.2006.051090

64. Goodwin PJ, Ennis M, Pritchard KI, Trudeau ME, Koo J, Madarnas $Y$, Hartwick W, Hoffman B, Hood N (2002). Fasting insulin and outcome in early-stage breast cancer: results of a prospective cohort study. J Clin Oncol 20(1): 42-51. doi: 10.1200/JCO.2002.20.1.42

65. Nanni O, Amadori D, De Censi A, Rocca A, Freschi A, Bologna A Gianni L, Rosetti F, Amaducci L, Cavanna L, Foca F, Sarti S, Serra P, Valmorri L, Bruzzi P, Corradengo D, Gennari A, investigators M (2019). Metformin plus chemotherapy versus chemotherapy alone in the firstline treatment of HER2-negative metastatic breast cancer. The MYME randomized, phase 2 clinical trial. Breast Cancer Res Treat 174(2): 433-442. doi: 10.1007/s10549-018-05070-2

66. Lashinger LM, Rossi EL, Hursting SD (2014). Obesity and resistance to cancer chemotherapy: interacting roles of inflammation and metabolic dysregulation. Clin Pharmacol Ther 96(4): 458-463. doi: 10.1038/clpt.2014.136 
67. Al Sayed MF, Amrein MA, Buhrer ED, Huguenin AL, Radpour R, Riether C, Ochsenbein AF (2019). T-cell-Secreted TNFalpha Induces Emergency Myelopoiesis and Myeloid-Derived Suppressor Cell Differentiation in Cancer. Cancer Res 79(2): 346-359. doi: 10.1158/0008-5472.CAN-17-3026

68. Murphy WJ, Longo DL (2019). The Surprisingly Positive Association Between Obesity and Cancer Immunotherapy Efficacy. JAMA 321(13): 1247. doi: 10.1001/jama.2019.0463

69. McQuade JL, Daniel CR, Hess KR, Mak C, Wang DY, Rai RR, Park JJ, Haydu LE, Spencer C, Wongchenko M, Lane S, Lee DY, Kaper M, McKean M, Beckermann KE, Rubinstein SM, Rooney I, Musib L, Budha N, Hsu J, Nowicki TS, Avila A, Haas T, Puligandla M, Lee S, Fang S, Wargo JA, Gershenwald JE, Lee JE, Hwu P, et al. (2018). Association of body-mass index and outcomes in patients with metastatic melanoma treated with targeted therapy, immunotherapy, or chemotherapy: a retrospective, multicohort analysis. Lancet Oncol 19(3): 310-322. doi: 10.1016/S1470-2045(18)30078-0

70. Doherty JR, Cleveland JL (2013). Targeting lactate metabolism for cancer therapeutics. J Clin Invest 123(9): 3685-3692. doi: 10.1172/JCl69741

71. Kim HS, Kim DM, Cha BS, Park TS, Kim KA, Kim DL, Chung $\mathrm{CH}$, Park $\mathrm{JH}$, Jang HC, Choi DS (2014). Efficacy of glimepiride/metformin fixeddose combination vs metformin uptitration in type 2 diabetic patients inadequately controlled on low-dose metformin monotherapy: A randomized, open label, parallel group, multicenter study in Korea. J Diabetes Investig 5(6): 701-708. doi: 10.1111/jdi.12201

72. Zhao T, Du H, Blum JS, Yan C (2016). Critical role of PPARgamma in myeloid-derived suppressor cell-stimulated cancer cell proliferation and metastasis. Oncotarget 7(2): 1529-1543. doi: 10.18632/oncotarget.6414

73. Hossain F, Al-Khami AA, Wyczechowska D, Hernandez C, Zheng L, Reiss K, Valle LD, Trillo-Tinoco J, Maj T, Zou W, Rodriguez PC, Ochoa AC (2015). Inhibition of Fatty Acid Oxidation Modulates Immunosuppressive Functions of Myeloid-Derived Suppressor Cells and Enhances Cancer Therapies. Cancer Immunol Res 3(11): 12361247. doi: 10.1158/2326-6066.CIR-15-0036

74. Park J, Lee SE, Hur J, Hong EB, Choi JI, Yang JM, Kim JY, Kim YC, Cho HJ, Peters JM, Ryoo SB, Kim YT, Kim HS (2015). M-CSF from Cancer Cells Induces Fatty Acid Synthase and PPARbeta/delta Activation in Tumor Myeloid Cells, Leading to Tumor Progression. Cell Rep 10(9): 1614-1625. doi: 10.1016/j.celrep.2015.02.024

75. Bonanni B, Puntoni $M$, Cazzaniga $M$, Pruneri $G$, Serrano $D$, Guerrieri-Gonzaga A, Gennari A, Trabacca MS, Galimberti V, Veronesi $P$, Johansson $H$, Aristarco V, Bassi F, Luini A, Lazzeroni M, Varricchio C, Viale G, Bruzzi P, Decensi A (2012). Dual effect of metformin on breast cancer proliferation in a randomized presurgical trial. J Clin Oncol 30(21): 2593-2600. doi: 10.1200/JCO.2011.39.3769

76. Messmer MN, Netherby CS, Banik D, Abrams SI (2015). Tumorinduced myeloid dysfunction and its implications for cancer immunotherapy. Cancer Immunol Immunother 64(1): 1-13. doi: 10.1007/s00262-014-1639-3

77. Gandhi L, Rodriguez-Abreu D, Gadgeel S, Esteban E, Felip E, De Angelis $F$, Domine $M$, Clingan $P$, Hochmair MJ, Powell SF, Cheng SY, Bischoff HG, Peled N, Grossi F, Jennens RR, Reck M, Hui R, Garon EB, Boyer M, Rubio-Viqueira B, Novello S, Kurata T, Gray JE, Vida J, Wei Z, Yang J, Raftopoulos H, Pietanza MC, Garassino MC, Investigators K(2018). Pembrolizumab plus Chemotherapy in Metastatic Non-SmallCell Lung Cancer. N Engl J Med 378(22): 2078-2092. doi: 10.1056/NEJMoa1801005

78. Schmid P, Adams S, Rugo HS, Schneeweiss A, Barrios $\mathrm{CH}$, Iwata $\mathrm{H}$, Dieras V, Hegg R, Im SA, Shaw Wright G, Henschel V, Molinero L, Chui SY, Funke R, Husain A, Winer EP, Loi S, Emens LA, Investigators IMT (2018). Atezolizumab and Nab-Paclitaxel in Advanced Triple-Negative
Breast Cancer. N Engl J Med 379(22): 2108-2121. doi: 10.1056/NEJMoa1809615

79. Heinhuis KM, Ros W, Kok M, Steeghs N, Beijnen JH, Schellens JHM (2019). Enhancing antitumor response by combining immune checkpoint inhibitors with chemotherapy in solid tumors. Ann Oncol 30(2): 219-235. doi: 10.1093/annonc/mdy551

80. Ding ZC, Munn DH, Zhou G (2014). Chemotherapy-induced myeloid suppressor cells and antitumor immunity: The Janus face of chemotherapy in immunomodulation. Oncoimmunology 3(8): e954471. doi: 10.4161/21624011.2014.954471

81. Ding ZC, Lu X, Yu M, Lemos H, Huang L, Chandler P, Liu K, Walters M, Krasinski A, Mack M, Blazar BR, Mellor AL, Munn DH, Zhou G (2014). Immunosuppressive myeloid cells induced by chemotherapy attenuate antitumor CD4+ T-cell responses through the PD-1-PD-L1 axis. Cancer Res 74(13): 3441-3453. doi: 10.1158/0008-5472.CAN-133596

82. Suzuki E, Kapoor V, Jassar AS, Kaiser LR, Albelda SM (2005). Gemcitabine selectively eliminates splenic $\mathrm{Gr}-1+/ \mathrm{CD} 11 \mathrm{~b}+$ myeloid suppressor cells in tumor-bearing animals and enhances antitumor immune activity. Clin Cancer Res 11(18): 6713-6721. doi: 10.1158/1078-0432.CCR-05-0883

83. Kodumudi KN, Woan K, Gilvary DL, Sahakian E, Wei S, Djeu JY (2010). A novel chemoimmunomodulating property of docetaxel: suppression of myeloid-derived suppressor cells in tumor bearers. Clin Cancer Res 16(18): 4583-4594. doi: 10.1158/1078-0432.CCR-10-0733

84. Vincent J, Mignot $\mathrm{G}$, Chalmin F, Ladoire S, Bruchard $\mathrm{M}$, Chevriaux A, Martin F, Apetoh L, Rebe C, Ghiringhelli F (2010). 5-Fluorouracil selectively kills tumor-associated myeloid-derived suppressor cells resulting in enhanced T cell-dependent antitumor immunity. Cancer Res 70(8): 3052-3061. doi: 10.1158/0008-5472.CAN-09-3690

85. Sistigu A, Viaud S, Chaput N, Bracci L, Proietti E, Zitvogel L (2011). Immunomodulatory effects of cyclophosphamide and implementations for vaccine design. Semin Immunopathol 33(4): 369383. doi: 10.1007/s00281-011-0245-0

86. Pelaez B, Campillo JA, Lopez-Asenjo JA, Subiza JL (2001). Cyclophosphamide induces the development of early myeloid cells suppressing tumor cell growth by a nitric oxide-dependent mechanism. J Immunol 166(11): 6608-6615. doi: 10.4049/jimmunol.166.11.6608

87. Mikyskova R, Indrova M, Pollakova V, Bieblova J, Simova J, Reinis M (2012). Cyclophosphamide-induced myeloid-derived suppressor cell population is immunosuppressive but not identical to myeloid-derived suppressor cells induced by growing TC-1 tumors. J Immunother 35(5): 374-384. doi: 10.1097/CJI.0b013e318255585a

88. Bass KK, Mastrangelo MJ (1998). Immunopotentiation with lowdose cyclophosphamide in the active specific immunotherapy of cancer. Cancer Immunol Immunother 47(1): 1-12. doi: $10.1007 / \mathrm{s} 002620050498$

89. Wada S, Yoshimura K, Hipkiss EL, Harris TJ, Yen HR, Goldberg MV, Grosso JF, Getnet D, Demarzo AM, Netto GJ, Anders R, Pardoll DM, Drake CG (2009). Cyclophosphamide augments antitumor immunity: studies in an autochthonous prostate cancer model. Cancer Res 69(10): 4309-4318. doi: 10.1158/0008-5472.CAN-08-4102

90. Diaz-Montero CM, Salem ML, Nishimura MI, Garrett-Mayer E, Cole DJ, Montero AJ (2009). Increased circulating myeloid-derived suppressor cells correlate with clinical cancer stage, metastatic tumor burden, and doxorubicin-cyclophosphamide chemotherapy. Cancer Immunol Immunother 58(1): 49-59. doi: 10.1007/s00262-008-0523-4

91. Wesolowski R, Duggan MC, Stiff A, Markowitz J, Trikha P, Levine KM, Schoenfield L, Abdel-Rasoul M, Layman R, Ramaswamy B, Macrae ER, Lustberg MB, Reinbolt RE, Mrozek E, Byrd JC, Caligiuri MA, Mace 
TA, Carson WE, 3rd (2017). Circulating myeloid-derived suppressor cells increase in patients undergoing neo-adjuvant chemotherapy for breast cancer. Cancer Immunol Immunother 66(11): 1437-1447. doi: 10.1007/s00262-017-2038-3

92. Kaewkangsadan V, Verma C, Eremin JM, Cowley G, Ilyas M, Eremin $O$ (2016). Crucial Contributions by $T$ Lymphocytes (Effector, Regulatory, and Checkpoint Inhibitor) and Cytokines (TH1, TH2, and TH17) to a Pathological Complete Response Induced by Neoadjuvant Chemotherapy in Women with Breast Cancer. J Immunol Res 2016: 4757405. doi: 10.1155/2016/4757405

93. Koinis F, Vetsika EK, Aggouraki D, Skalidaki E, Koutoulaki A, Gkioulmpasani M, Georgoulias V, Kotsakis A (2016). Effect of First-Line Treatment on Myeloid-Derived Suppressor Cells' Subpopulations in the Peripheral Blood of Patients with Non-Small Cell Lung Cancer. J Thorac Oncol 11(8): 1263-1272. doi: 10.1016/j.jtho.2016.04.026

94. Kanterman J, Sade-Feldman M, Biton M, Ish-Shalom E, Lasry A, Goldshtein A, Hubert A, Baniyash M (2014). Adverse immunoregulatory effects of 5FU and CPT11 chemotherapy on myeloid-derived suppressor cells and colorectal cancer outcomes. Cancer Res 74(21): 6022-6035. doi: 10.1158/0008-5472.CAN-14-0657

95. Damuzzo V, Solito S, Pinton L, Carrozzo E, Valpione S, Pigozzo J, Arboretti Giancristofaro R, Chiarion-Sileni V, Mandruzzato S (2016). Clinical implication of tumor-associated and immunologica parameters in melanoma patients treated with ipilimumab. Oncoimmunology 5(12): e1249559. doi: $10.1080 / 2162402 \times .2016 .1249559$

96. Wanderley CW, Colon DF, Luiz JPM, Oliveira FF, Viacava PR, Leite CA, Pereira JA, Silva CM, Silva CR, Silva RL, Speck-Hernandez CA, Mota JM, Alves-Filho JC, Lima-Junior RC, Cunha TM, Cunha FQ (2018). Paclitaxel Reduces Tumor Growth by Reprogramming TumorAssociated Macrophages to an M1 Profile in a TLR4-Dependent Manner. Cancer Res 78(20): 5891-5900. doi: 10.1158/0008-5472.CAN$17-3480$ 